\title{
Giant Onychomatricoma of the Great Toenail: Case Report and Review Focusing on Less Common Variants
}

\author{
Christos Prevezas $^{\mathrm{a}}$ Ioanna Triantafyllopoulou ${ }^{\mathrm{a}}$ Helena Belyayeva ${ }^{\mathrm{a}}$ \\ Dimitrios Sgouros $^{a}$ Stephanos Konstantoudakis ${ }^{b}$ Ioannis Panayiotides ${ }^{b}$ \\ Dimitrios Rigopoulos ${ }^{\mathrm{a}}$
}

${ }^{a}$ Nail Disorders Unit, Second Department of Dermatology, and ${ }^{\mathrm{b}}$ Second Department of Pathology, Attikon University Hospital, Athens, Greece

\section{Key Words}

Onychomatricoma - Giant · Uncommon type · Nail tumor

\begin{abstract}
Onychomatricoma is a rare benign fibroepithelial filamentous tumor originating from the nail matrix. It typically presents with the clinical tetrad of xanthonychia, pachyonychia, proximal splinter hemorrhages and increased transverse overcurvature of the nail plate. The giant variant can easily confuse the clinician due to its extensive nail dystrophy that can mask the characteristic features of this tumor. Benign (fibrokeratoma, ungual fibroma, onycholytic matricoma) and malignant entities (Bowen's disease, squamous cell carcinoma, onycholytic carcinoma) are mimics of the disease. Nail surgery can facilitate the diagnosis, which should always be confirmed by histology, as rare variants do exist.
\end{abstract}

(c) 2016 S. Karger AG, Basel
() 2016 S. Karger AG, Basel

2296-9195/16/0014-0202\$39.50/0

\section{Introduction}

Onychomatricoma $(\mathrm{OM})$ is a rare benign fibroepithelial filamentous tumor originating from the nail matrix. Although first described by Baran and Kint [1] in 1992, there have been approximately 200 cases reported in the literature so far. Patients are usually females around their fifties who are finally diagnosed years after the tumor's original appearance as the latter is slow-growing and painless, leading to progressive nail dystrophy [2]. OM typically presents with the clinical tetrad of xanthonychia, pachyonychia, proximal splinter hemorrhages and increased transverse overcurvature of the nail plate [3]. Nevertheless, it seems that $\mathrm{OM}$ is a 'proteic' tumor that can obtain misleading features either clinically and/or histologically.

The aim of this article is to present the current knowledge on OM while focusing on less common variants and disease mimics. At the same time we present an interesting case, encountered in our nail unit, which triggered us to write this review.

\section{KARGER 125}

E-Mail karger@karger.com www.karger.com/sad
Dr. Christos Prevezas

Nail Disorders Unit, Second Department of Dermatology Attikon University Hospital

1 Rimini Street, POB 12462, GR-124 62 Athens (Greece)

E-Mail chrisprevezas@yahoo.com 


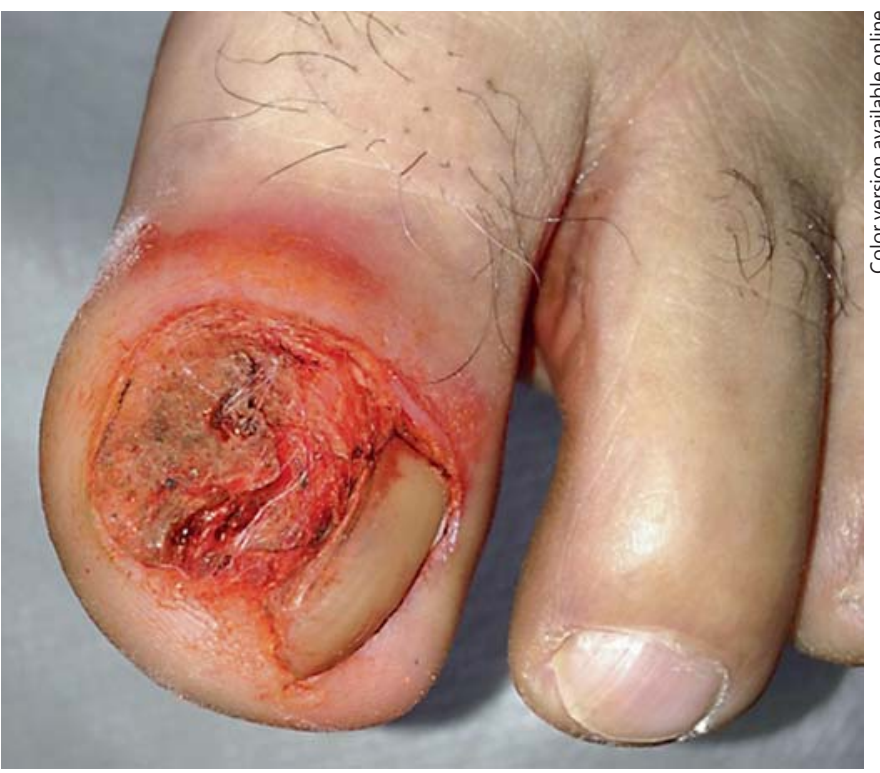

Fig. 1. Extensive nail dystrophy with marked pachyonychia, nail plate fracture and cavities accompanied by paronychia (the red color is due to chronic application of iodine-based antiseptic solution).

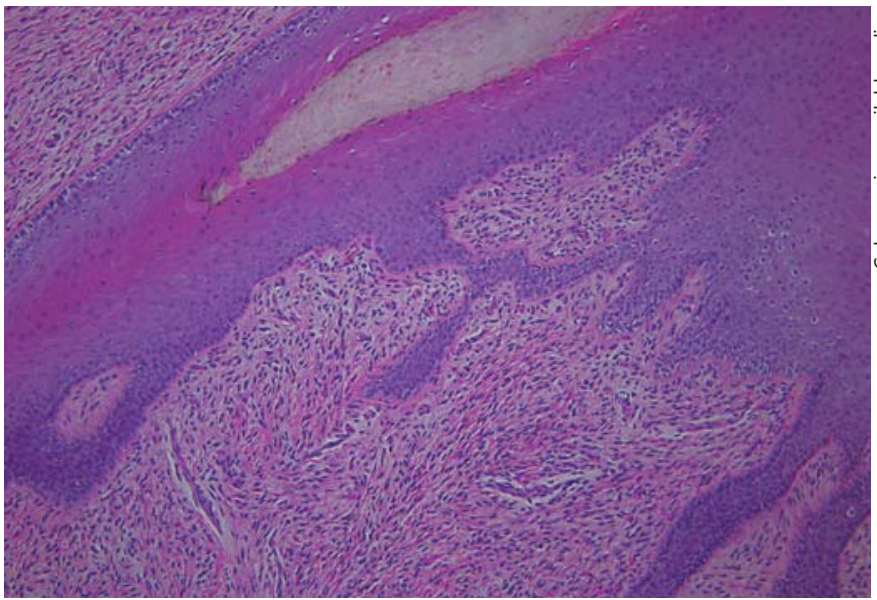

Fig. 2. An overview of the tumor, together with the overlying keratinizing, nail-type squamous epithelium (hematoxylin and eosin staining, $\times 10)$.

\section{Case Report}

A 73-year-old man, a Caucasian farmer, was referred to our clinic by a colleague for investigation of nail dystrophy concerning his left great toenail. The existing nail pathology was asymptomatic and had been present for more than a decade. He reported multiple minor traumas and an iatrogenic total avulsion followed by complete tumor recurrence. The patient's medical history was otherwise unremarkable except for the fact that he was under medication for high arterial blood pressure.

Giant Onychomatricoma and Uncommon Variants

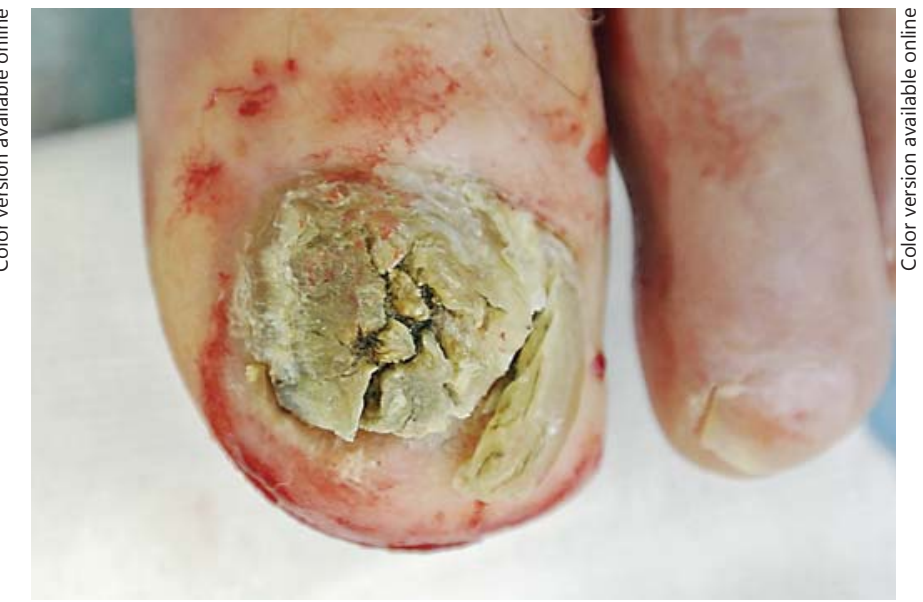

Fig. 3. Preoperative image. Nail plate thickening is now more prominent.

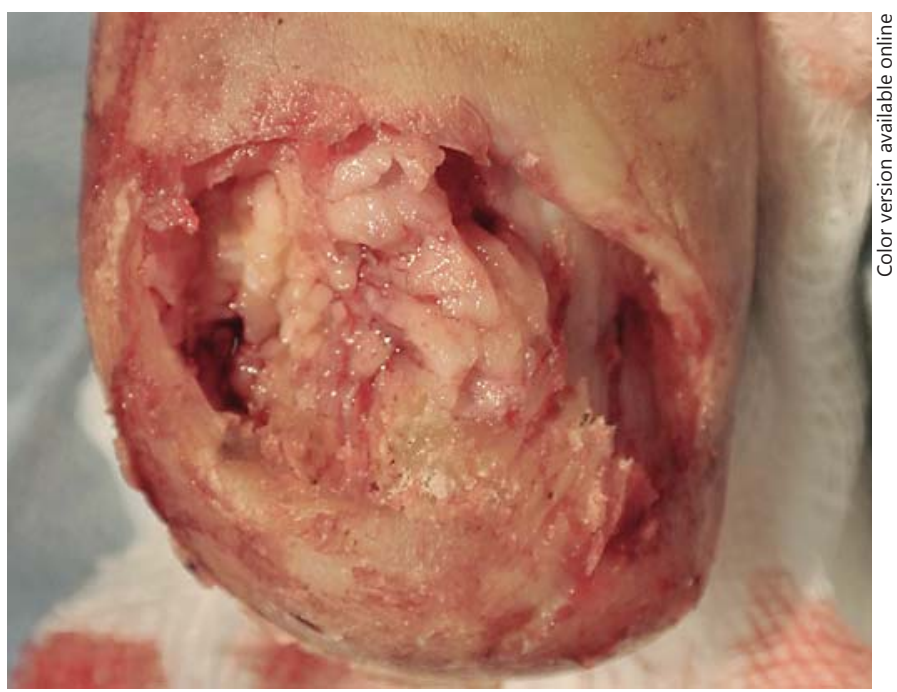

Fig. 4. Intraoperative image showing the tumor's finger-like projections.

Clinical examination revealed an almost totally dystrophic nail with marked pachyonychia along with a central river-like channel of onychorrhexis surrounded by open-roof woodworm cavities. Additionally, the nail plate exhibited globule-like hemorrhagic aggregations and increased overcurvature of both axes. Finally, mild paronychia was noted involving both the proximal and lateral nail folds (fig. 1).

In order to exclude squamous cell carcinoma, which was our primary concern, we performed a lateral longitudinal biopsy of the nail unit. Histology showed the lesion to have the morphological characteristics of an OM, without any atypical cells or necrosis. Mitotic activity was unremarkable (fig. 2). Moreover, an $\mathrm{X}$-ray of the affected toe did not show any alteration of the bone structure. 


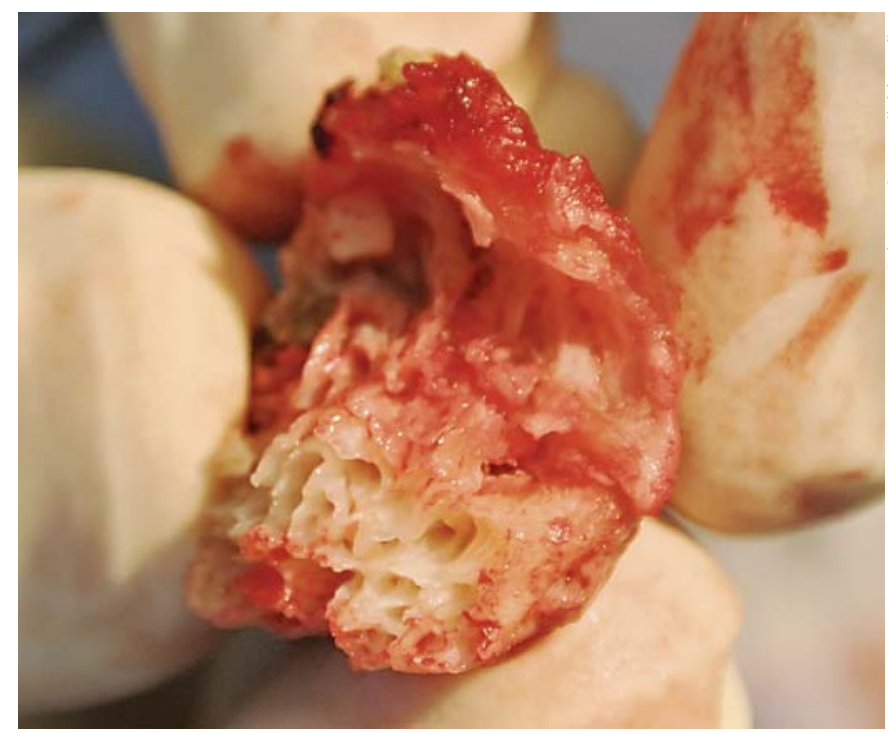

Fig. 5. Multiple woodworm cavities occupying the nail plate.

The patient was informed about the benign nature of his pathology and was offered the option of surgical tumor removal. He returned 1 year after his first consultation, willing to proceed. Figure 3 shows the preoperative image with an increase in nail plate hyperkeratosis and more prominent cavities distally. During surgery, the proximal nail fold was elevated by performing two incisions between the proximal and the lateral fold. Consequently, the nail plate was removed, exposing the matricial tumor with its multiple glove-like digitations (fig. 4) whose imprint was clearly seen at the hyperkeratotic nail plate (fig. 5). The tumor was dissected tangentially and the proximal nail fold was sutured back to its place. A perforated Vaseline gauze was placed between the matrix and the nail fold to prevent pterygium formation. The result of the pathology report was again that of an OM. The patient was followed up for 1 year with no recurrence.

\section{Discussion}

OM's rarity and diversity have been attracting the interest of nail 'connoisseurs'. Its origin remains controversial while several clinical and histological variants have been described throughout the years, adding polymorphism to its entity.

Following the article of Baran and Kint in [1] 1992 where they first named the tumor 'onychomatrixoma', Haneke and Franken [4] in 1995 coined the term 'onychomatricoma' due to its histological features. Since then, there have been sporadic reports with single or few patients, the largest series being those of Perrin et al. [3, 5] (12 and 19 patients, respectively) and, recently, those of
Lesort et al. [6] (34 patients) and Di Chiacchio et al. [7] (30 patients).

The exact origin of OM remains controversial. It has been hypothesized that it represents a reactive process and not an actual tumor or that it can be a hamartoma mimicking the nail matrix $[3,4]$. By analyzing the pattern of hair keratin expression in three cases, Perrin et al. [8] suggested a differentiation towards the nail bed and isthmus. Recently, Wang et al. [9] reported an OM mainly derived from the nail bed. This concept of an epithelial onychogenic tumor with onychogenic mesenchyme was further supported by Lee [10] who found that CD10, a marker of onychodermis, is also expressed in the stroma of OM, thus concluding that the tumor could probably derive from the onychodermis itself.

The tumor typically affects Caucasian women around their fifties; it is rare in non-Caucasian descendants [11]. There has been only one presentation in a child so far [12]. The fingers are commonly involved (75\%), with the index finger accounting for two thirds of the cases. There is a mean delay of 12.5 years before diagnosis as the tumor is usually asymptomatic and slow-growing or has been misdiagnosed as onychomycosis and treated unsuccessfully by other colleagues [7].

OM typically presents with xanthonychia (yellow discoloration of the nail plate), pachyonychia (nail plate thickening), proximal splinter hemorrhages, increased transverse overcurvature of both axes and cavities apparent at the distal edge of the nail plate. Sometimes a nodule is visible underneath the proximal nail fold [13].

The diagnosis of OM can be facilitated by several modalities. Dermoscopy has been proven to be a valuable tool [6]. Several criteria are often present such as longitudinal parallel white lines, parallel lesion edges, splinter hemorrhages, dark dots, free-edge nail pitting and thickening of the free edge. High-frequency ultrasound [14] shows a hypoechogenic area affecting the matrix and a hyperechogenic one that corresponds to the finger-like projections. In MRI [15], the matricial part of the tumor depicts a low signal while its projections show a high signal. Clippings of the free edge of the nail plate with subsequent histology have also been suggested as a fast, less expensive and minimally invasive technique [16]. Recently, the nail plate of patients with OM has been examined with in vivo reflectance confocal microscopy [17] prior to surgical excision. This method revealed longitudinal dark areas and bright/grey lines, forming channellike structures.

Although the above modalities can point out to the diagnosis, the latter should always be confirmed by histol- 
ogy. $\mathrm{OM}$ is seen as a fibroepithelial tumor that exhibits two distinct anatomical zones (proximal and distal) and a two-layered (superficial and deep) stroma containing several mast cells [3]. The proximal zone, situated beneath the proximal nail fold, extends from the root of the tumor to the cuticle. This zone is characterized by a deep epithelial invagination filled with a thick $\mathrm{V}$-shaped keratogenous zone. The nail plate lacks all cavities and presents an undulating inferior border. The distal zone corresponds to the lunula and is characterized by multiple 'glove finger' digitations surrounded by matrix epithelium. These digitations fill the nail plate, generating cavities occupied by serous fluid distally. Connective tissue projections, in turn, expand deeply into the dermis. The stroma is biphasic with a fibrillar and cellular superficial layer and a deeper one, less cellular with denser collagen bundles.

Immunohistochemical markers and proper sectioning can confirm the diagnosis. The tumor shows expression of CD34 but not CD99 [5]. Additionally, three-dimensional spatial reconstitution is helpful as the tumor varies in proximal and distal sections, presenting a foliated pattern on proximal transverse section and a glove fingerlike pattern on distal longitudinal section [18].

The differential diagnosis is extensive [19], comprising both benign (fibrokeratoma, ungual fibroma, etc.) and malignant entities like Bowen's disease and squamous cell carcinoma.

Surgical excision is the treatment of choice. Complete excision [20] has been primarily suggested. Taking into account the benign nature of the tumor and the risk of permanent dystrophy, tangential excision [21] seems more appealing. The nail fold is reclined by performing two lateral oblique incisions at the junction of the proximal and lateral nail folds. The nail plate is then avulsed, exposing the tumor with its finger-like projections. The tumor is shaved tangentially from the matrix with a Teflon-coated blade. Finally, the fold is secured back to its place with non-absorbable sutures. Care is taken to avoid pterygium formation by placing a Vaseline gauze between the proximal nail fold and the matrix. The gauze is removed 3 weeks later. Mohs surgery [22] has been also used in one case in order to limit the probability of recurrence.

Apart from its typical form, OM can adopt additional atypical, clinical or histological, features or coexist with other pathologies, making its diagnosis more perplexing.

Giant Onychomatricoma and Uncommon

Variants

\section{Atypical Clinical Features/Variants and Associated}

Diseases (table 1)

In 2000, Fayol et al. [23] were the first to introduce five cases of OM presenting with the atypical features of longitudinal melanonychia, cutaneous horn and onychomycosis infection from Trichophyton or Fusarium. They speculated that fungal infection could trigger tumor formation or that the propagation of the former could be facilitated by the induced nail dystrophy. The clinical sign of longitudinal melanonychia has also been reported by Fanti et al. [24] as well as by Di Chiacchio et al. [7], Wynes et al. [25] and Lesort et al. [6], the latter stating that other chromonychias such as leukonychia or erythronychia might be present.

Although benign in the majority of cases, melanonychia can be associated with underlying malignancy. In 2002, Baran and Perrin [26] reported a variant of Bowen's disease clinically simulating pigmented OM. Therefore, a biopsy is always warranted when facing such a case.

Another interesting association is the coexistence of $\mathrm{OM}$ and pterygium [27, 28]. Baran and Perrin [26] clearly demonstrated that there are two distinct scenarios. In the first scenario, a pterygium is formed when the tumor covers the ventral aspect of the proximal nail fold, including the angle where it meets the dorsal epidermis. This form mimics the pterygium found in lichen planus. On the other hand, when the proximal nail fold is spared, the latter reacts to the pressure exerted by the matricial tumor. This particular form mimics onychogenic Bowen's disease.

Giant OM similar to our case has been sparsely reported in the literature [29-31]. Delay of diagnosis and associated recurrent trauma have been hypothesized to promote tumor growth, rendering the differential diagnosis more difficult. Perioperative exploration usually solves the riddle when the matricial finger-like projections and nail plate channels appear after nail avulsion.

Finally, OM has also been reported in the literature to present as ingrown nail [2] or subungual hematoma [32] or to coexist with a glomus tumor [33].

\section{Histological Variants (table 2)}

Variations in stromal cellularity and nuclear pleomorphism led Ko et al. [34] to propose a different nomenclature comprising three categories: (1) unguioblastoma (prominent epithelial component), (2) unguioblastic fibroma (prominent stromal component), and (3) atypical unguioblastic fibroma (stromal nuclear pleomorphism, atypia and increased mitotic activity).

Skin Appendage Disord 2015;1:202-208 
Table 1. Atypical clinical variants and associated diseases

\begin{tabular}{|c|c|c|}
\hline Article & Additional clinical feature(s) & Associated disease \\
\hline Fayol et al. [23] & $\begin{array}{l}\text { longitudinal melanonychia ( } 3 \text { cases }) \\
\text { cutaneous horn ( } 1 \text { case }) \\
\text { - }\end{array}$ & $\begin{array}{l}\text { Trichophyton onychomycosis (in } 2 / 3 \text { cases) } \\
- \\
\text { Fusarium onychomycosis ( } 1 \text { case) }\end{array}$ \\
\hline Fanti et al. [24] & longitudinal melanonychia ( 1 case) & - \\
\hline Lesort et al. [6] & $\begin{array}{l}\text { longitudinal melanonychia ( } 8 \text { cases }) \\
\text { leukonychia ( } 20 \text { cases) } \\
\text { erythronychia ( } 8 \text { cases }) \\
\text { paronychia ( } 10 \text { cases })\end{array}$ & $\begin{array}{l}- \\
- \\
-\end{array}$ \\
\hline Saranya et al. [30] & giant variant ( 1 case) & - \\
\hline Chiheb et al. [31] & giant variant ( 2 cases) & - \\
\hline Tavares et al. [2] & ingrown nail (1 case) & - \\
\hline Raison-Peyron et al. [32] & $\begin{array}{l}\text { subungual hematoma (1 case) } \\
-\end{array}$ & $\begin{array}{l}\text { glomus tumor (1 case) }\end{array}$ \\
\hline
\end{tabular}

Table 2. Histological variants

\begin{tabular}{lll}
\hline Article & Variant & Features \\
\hline Ko et al. [34] & $\begin{array}{l}\text { unguioblastoma } \\
\text { unguioblastic fibroma } \\
\text { atypical unguioblastic fibroma }\end{array}$ & $\begin{array}{l}\text { prominent epithelial component } \\
\text { prominent stromal component } \\
\text { stromal nuclear pleomorphism, atypia and increased mitotic activity }\end{array}$ \\
\hline Stewart et al. [35] & myxoid type & myxoid stroma associated with the fibrous component \\
\hline Perrin et al. [5] & pleomorphic variant & $\begin{array}{l}\text { wreath-like multinucleated cells } \\
\text { zonal distribution of mast cells in the superficial stromal layer } \\
\text { membranous expression of CD34 }\end{array}$ \\
\hline $\begin{array}{l}\text { Fernandez-Flores and } \\
\text { Barja-Lopez [36] }\end{array}$ & pleomorphic variant & $\begin{array}{l}\text { wreath-like multinucleated cells } \\
\text { zonal distribution of mast cells in the superficial stromal layer } \\
\text { membranous expression of CD34 }\end{array}$ \\
\hline
\end{tabular}

Table 3. Rare benign and malignant OM mimics

\begin{tabular}{lll}
\hline Article & Clinical presentation & Nail pathology \\
\hline Baran and Perrin [26] & pigmented OM & pigmented Bowen's disease \\
\hline Spaccarelli et al. [37] & typical features of OM & onychocytic matricoma (hypopigmented type) \\
\hline Perrin et al. [38] & pigmented OM (longitudinal pachymelanonychia) & onychocytic matricoma (pigmented type) \\
\hline Perrin et al. [39] & pigmented OM (longitudinal pachymelanonychia) & onychocytic carcinoma \\
\hline
\end{tabular}


Less common variants have also been advocated. Stewart et al. [35] reported an OM with prominent myxoid stroma associated with the fibrous component. Perrin et al. [5] and Fernandez-Flores and Barja-Lopez [36] described a pleomorphic variant with wreath-like multinucleated cells along with zonal distribution of mast cells in the superficial stromal layer and membranous expression of CD34.

\section{Rare Benign and Malignant Mimics (table 3)}

Finally, uncommon benign or malignant nail tumors can clinically simulate an OM. Pigmented Bowen's disease has already been mentioned. Additionally, onychocytic matricoma and its in situ malignant variant, onychocytic carcinoma, are two rare clinical mimics that have been recently described by Spaccarelli et al. [37] and Perrin et al. [38, 39]. These matricial acanthomas present as monodactylous longitudinal pachyonychia combined with xantholeukonychia or melanonychia. Although these pathologies can be distinguished only by histology, it appears that longitudinal pachymelanonychia is more frequently associated with malignancy.
Over the years, the paucity of OM cases has been replaced by numerous reports shedding more light to this interesting entity. Clinical suspicion should always be confirmed by histology, as very rare malignant variants do exist. Interestingly, although many years have passed since its first description, there has been no report of malignant transformation so far. We conclude that extensive surgery or expensive modalities, as first-line treatment, should be avoided when deciding to treat this after all benign tumor.

\section{Statement of Ethics}

The patient's consent has been obtained.

\section{Disclosure Statement}

The authors have no conflicts of interest to disclose.

\section{References}

1 Baran R, Kint A: Onychomatrixoma. Filamentous tufted tumour in the matrix of a funnel-shaped nail: a new entity (report of three cases). Br J Dermatol 1992;126:510-515.

2 Tavares GT, Chiacchio NG, Chiacchio ND, Souza MV: Onychomatricoma: a tumor unknown to dermatologists. An Bras Dermatol 2015;90:265-267.

3 Perrin CH, Goettmann S, Baran R: Onychomatricoma: clinical and histopathologic findings in 12 cases. J Am Acad Dermatol 1998;39: 560-564.

4 Haneke E, Franken J: Onychomatricoma. Dermatol Surg 1995;21:984-987.

5 Perrin C, Baran R, Balaguer T, Chignon-Sicard B, Cannata GE, Petrella T, Michiels JF: Onychomatricoma: new clinical and histological features. A review of 19 tumors. Am J Dermatopathol 2010;32:1-8.

6 Lesort C, Debarbieux S, Duru G, Dalle S, Poulhalon N, Thomas L: Dermoscopic features of onychomatricoma: a study of 34 cases. Dermatology 2015;231:177-183.

7 Di Chiacchio N, Tavares GT, Tosti A, Di Chiacchio NG, Di Santis E, Alvarenga L, Stuhr P, De Farias D: Onychomatricoma: epidemiological and clinical findings in a large series of 30 cases. Br J Dermatol 2015;173:1305-1307.

8 Perrin C, Langbein L, Schweizer J, Cannata GE, Balaguer T, Chignon-Sicart B, Garzon JM, Benchetrit M, Michiels JF: Onychomatri- coma in the light of the microanatomy of the normal nail unit. Am J Dermatopathol 2011; 33:131-139.

9 Wang L, Gao T, Wang G: Nail bed onychomatricoma. J Cutan Pathol 2014;41:783-786.

10 Lee DY: The relation of onychomatricoma to onychodermis in the nail unit. Ann Dermatol 2013;25:394-395.

11 Tosti A, Piraccini BM, Calderoni O, Fanti PA, Cameli N, Varotti E: Onychomatricoma: report of three cases, including the first recognized in a colored man. Eur J Dermatol 2000; 10:604-606.

12 Piraccini BM, Antonucci A, Rech G, Starace M, Misciali C, Tosti A: Onychomatricoma: first description in a child. Pediatr Dermatol 2007;24:46-48.

13 Richert B, André J: Onychomatricoma (in French). Ann Dermatol Venereol 2011;138: 71-74.

14 Drape JL, Goettmann S, Chevrot A, Bittoun J, Baran R: Ultrasonography and magnetic resonance imaging of the paronychia; in Baran R, Dawber R, Haneka E, Toshi A, Bristow I, Dunitz M (eds): A Text Atlas of Nail Disorders. London, Taylor \& Francis, 2003, p 286.

15 Goettmann S, Drape JL, Baran R, Perrin C, Haneke E, Belaich S: Onychomatricome: deux nouveaux cas: intérêt de la résonance magnétique nucléaire. Ann Dermatol Venereol 1994;121:S145.
16 Miteva M, de Farias DC, Zaiac M, Romanelli P, Tosti A: Nail clipping diagnosis of onychomatricoma. Arch Dermatol 2011;147:11171118.

17 Sanchez MI, Hu S, Miteva M, Tosti A: Onychomatricoma has channel-like structures on in vivo reflectance confocal microscopy. J Eur Acad Dermatol Venereol 2014;28:1560-1562.

18 Poojary SA, Halwai V: A tumor hidden beneath the nail plate: report of a rare case of onychomatricoma with three-dimensional histopathological analysis and immunohistochemical study. Indian J Dermatol 2015;60: 212.

19 Morales-Cardona CA, Luque-Acevedo AA, Bermúdez-Bula LF: Onychomatricoma: an often misdiagnosed tumor of the nails. Cutis 2015;96:121-124.

20 Van Holder C, Dumontier C, Abimelec P: Onychomatricoma. J Hand Surg 1999;24: 120-121.

21 Cogrel O: Shave biopsy for a digital onychomatricoma (in French). Ann Dermatol Venereol 2014;141:634-635.

22 Graves MS, Anderson JK, LeBlanc KG Jr, Sheehan DJ: Utilization of Mohs micrographic surgery in a patient with onychomatricoma. Dermatol Surg 2015;41:753-755.

23 Fayol J, Baran R, Perrin C, Labrousse F: Onychomatricoma with misleading features. Acta Derm Venereol 2000;80:370-372. 
24 Fanti PA, Dika E, Ismaili A, Barisani A, Piraccini BM: A longitudinal pigmented band on the right index fingernail. Clin Exp Dermatol 2015;40:344-346.

25 Wynes J, Wanat KA, Huen A, Mlodzienski AJ, Rubin AI: Pigmented onychomatricoma: a rare pigmented nail unit tumor presenting as longitudinal melanonychia that has potential for misdiagnosis as melanoma. J Foot Ankle Surg 2015;54:723-725.

26 Baran R, Perrin C: Bowen's disease clinically simulating an onychomatricoma. J Am Acad Dermatol 2002;47:947-949.

27 Perrin C, Baran R: Onychomatricoma with dorsal pterygium: pathogenic mechanisms in 3 cases. J Am Acad Dermatol 2008;59:990994.

28 Goettmann S, Zaraa I, Moulonguet I: Onychomatricoma with pterygium aspect: unusual clinical presentation. Acta Derm Venereol 2006;86:369-370.
29 Estrada-Chavez G, Vega-Memije ME, Toussaint-Caire S, Rangel L, Dominguez-Cherit J: Giant onychomatricoma: report of two cases with rare clinical presentation. Int J Dermatol 2007;46:634-636.

30 Saranya M, Saritha M, Karthikeyan K: Ram's horn nail - giant onychomatricoma treated by complete surgical excision - a rare case report. Indian J Dermatol 2015;60:523.

31 Chiheb S, Amri S, Naciri Bennani B, Richert B, Mernissi F, Zamiati S, Benchikhi H: Onychomatricoma (in French). Ann Dermatol Venereol 2014;141:79-82.

32 Raison-Peyron N, Alirezai M, Meunier L, Barneon G, Meynadier J: Onychomatricoma: an unusual cause of nail bleeding. Clin Exp Dermatol 1998;23:138.

33 Kallis P, Miteva M, Patel T, Zaiac M, Tosti A: Onychomatricoma with concomitant subungual glomus tumor. Skin Appendage Disord 2015;1:14-17.

34 Ko CJ, Shi L, Barr RJ, Mölne L, TernestenBratel A, Headington JT: Unguioblastoma and unguioblastic fibroma - an expanded spectrum of onychomatricoma. J Cutan Pathol 2004;31:307-311.
35 Stewart CL, Sobanko JF, Rubin AI: Myxoid onychomatricoma: an unusual variant of a rare nail unit tumor. Am J Dermatopathol 2015;37:473-476.

36 Fernandez-Flores A, Barja-Lopez JM: Pleomorphic onychomatricoma. J Cutan Pathol 2014;41:555-560.

37 Spaccarelli N, Wanat KA, Miller CJ, Rubin AI: Hypopigmented onychocytic matricoma as a clinical mimic of onychomatricoma: clinical, intraoperative and histopathologic correlations. J Cutan Pathol 2013;40:591-594.

38 Perrin C, Cannata GE, Bossard C, Grill JM, Ambrossetti D, Michiels JF: Onychocytic matricoma presenting as pachymelanonychia longitudinal. A new entity (report of five cases). Am J Dermatopathol 2012;34:54-59.

39 Perrin C, Langbein L, Ambrossetti D, Erfan N, Schweizer J, Michiels JF: Onychocytic carcinoma: a new entity. Am J Dermatopathol 2013;35:679-684. 